\title{
Practical study on Japanese building construction management by avoiding risk to environment and safety
}

\author{
Hiroyuki Wariishi ${ }^{1, \mathrm{a}}$ and Takehiro Tanaka ${ }^{1}$ \\ ${ }^{1}$ Toyo University, Japan
}

\begin{abstract}
It is essential in building construction management to prevent risk from the viewpoint of both environment and safety. This study suggests the significance of building construction management which places emphasis on risk prevention for the sake of environment and safety, with the introduction of Japanese efficient operation methods to simultaneously conduct environmental management, safety management and risk management, in addition to practical measures for heatstroke which is a serious summer issue of building construction management.
\end{abstract}

\section{Introduction}

It is essential in building construction management to prevent risk from the viewpoint of both environment and safety. This study suggests the significance of building construction management which places emphasis on risk prevention for the sake of environment and safety, with the introduction of Japanese efficient operation methods to simultaneously conduct environmental management (ISO14000 family), safety management (ISO45001) and risk management (ISO31000). In this paper, these ISOs, particularly ISO45001 Occupational Health and Safety Management Systems which was internationally standardized on March 12, 2018, are reviewed, in addition to practical measures for heatstroke which is a serious summer issue of building construction management.

\section{Compatibility of ISOs related to environment and safety}

\subsection{Environmental management (ISO14000 family)}

The ISO14000 family of standards provides practical tools for companies and organizations of all kinds looking to manage their environmental responsibilities. ISO14001 and its supporting standards such as ISO14006 focus on environmental systems to achieve this. The other standards in the family focus on specific approaches such as audits, communications, labelling and life cycle analysis, as well as environmental challenges such as climate change.

The ISO 14000 family of standards are developed by ISO Technical Committee ISO/TC 207 and its various subcommittees.

\subsection{Occupational health and safety management systems (ISO45001)}

It is essential in building construction management to prevent risk from the viewpoint of both environment and safety. In this light, ISO45001 was newly issued on March 12, 2018 as the international standard of occupational health and safety management systems. The world's much anticipated International Standard for Occupational Health and Safety (OH\&S) has just been published, and is set to transform workplace practices globally.

ISO 45001:2018, Occupational health and safety management systems - Requirements with guidance for use, provides a robust and effective set of processes for improving work safety in global supply chains. Designed to help organizations of all sizes and industries, the new International Standard is expected to reduce workplace injuries and illnesses around the world.

According to 2017 calculations by the International Labour Organization (ILO), 2.78 million fatal accidents occur at work yearly. This means that, every day, almost 7,700 persons die of work-related diseases or injuries. Additionally, there are some 374 million non-fatal work-related injuries and illnesses each year, many of these resulting in extended absences from work. This paints a sober picture of the modern workplace - one where workers can suffer serious consequences as a result of simply "doing their job".

ISO 45001 hopes to change that. It provides governmental agencies, industry and other affected stakeholders with effective, usable guidance for improving worker safety in countries around the world. By means of an easy-to-use framework, it can be applied to both captive and partner factories and production facilities, regardless of their location. It has not been long since the standard was published and thus its particulars

\footnotetext{
*Corresponding author: ${ }^{\text {* }}$ whtaan@nifty.com
} 
are referred to as a guideline, but they are indispensable for building construction management.

\subsection{Risk management (ISO31000)}

There are some ISOs which should be mentioned when it comes to discussion about the significance of compatibility of ISOs related to environment and safety.

One among them is ISO31000. ISO 31000, Risk management - Guidelines, provides principles, framework and a process for managing risk. It can be used by any organization regardless of its size, activity or sector. Using ISO 31000 can help organizations increase the likelihood of achieving objectives, improve the identification of opportunities and threats and effectively allocate and use resources for risk treatment.

However, ISO 31000 cannot be used for certification purposes, but does provide guidance for internal or external audit programs. Organizations using it can compare their risk management practices with an internationally recognized benchmark, providing sound principles for effective management and corporate governance.

\subsection{Efficient management and implementation with compatible ISOs related to environment and safety}

The environmental management, the occupational health and safety management systems and the risk management discussed above in Section 2 are ISO international standards for management. They have certain contents and items in common, and therefore it is possible to apply them to an entire organization as well as to a specific division, project or activity any time. In addition, because the concept of continuous improvement by following the managerial basics of "Plan-Do-Check-Action" is adopted, the compatible ISOs are indispensable for the environment and safety management and implementation.

\section{Risk avoidance measures for building construction management in Japan}

It is essential for any organizations in any country to avoid risks. In this section, risk avoidance measures for building construction management in Japan are introduced.

Building construction management brings many risks to environment and safety. Figure 1 shows risk response. As the figure indicates, there are roughly four ways to manage risk: reduction, retention, avoidance, and transfer.

(1) Risk avoidance: This means the action of removing any factors which may create a risk. It is also called risk elimination.

(2) Risk reduction: Measures are taken to diminish the likelihood of risk occurrence or to minimize the effect of risk if it occurs, or to achieve the both. For example, seismic retrofit methods are considered as appropriate measures to reduce the likelihood of such a risk that an earthquake brings down a manufacturing plant and cripples its operation for several months. To minimize the effect of the same risk, it is suggested to increase the operation capacity of another plant and produce substitutes.

(3) Risk transfer: Literally, risk is shifted to another party. It is also called risk sharing, and one of the most typical measures is the purchase of an insurance policy. The use of outsourcing of professional services is one of means as well.

(4) Risk retention: It involves accepting risk without taking any measures. This act is chosen when the degree of a given risk is considered acceptable, or when it is determined that the risk has to be accepted because there is no plausible measures.

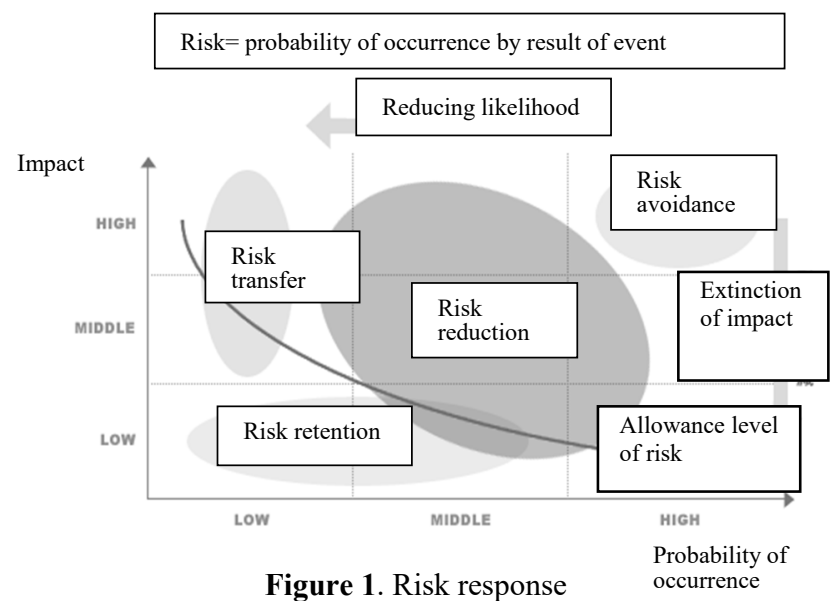

\section{Japanese building construction management to prevent heatstroke}

This section presents approaches to the prevention of heatstroke through efficient management and implementation by taking advantage of the compatibility of ISOs related to environment and safety discussed above in Section 2. Especially, since ISO45001 was newly issued on March 12, 2018 as the international standard of occupational health and safety management systems, Japan has been striving to efficiently avoid risks by promptly introducing ISOs related to environment and safety.

The mortality in the construction industry is increasing in comparison with other industries. Also, it has been found out that the number of heatstroke cases has increased due to aging among constructors on one hand, and global warming under the influence of abnormal weather and other factors on the other hand. The rainy season particular to Japan and the summer season also have some impact. It is hoped to take appropriate measures to deal with the situation by conducting on-site environmental research, and compare the results with those of China and other Asian nations. 


\subsection{Heatstroke-related fatal workplace accidents}

\subsubsection{Change in the death toll resulting from heatstroke (2008-2015)}

As Figure 2 illustrates, the largest number of deaths caused by heatstroke at work from 2005 to 2016 was 47 cases registered in 2010, followed by the second largest of 30 cases in 2013. The number of heatstroke victims in other years stood mostly around 20. This can be associated with the aging society and global warming.

persons

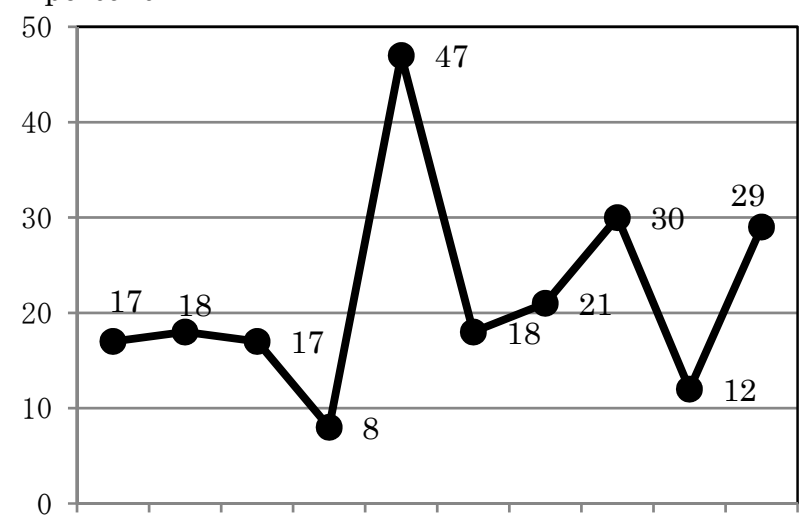

2006200720082009201020112012201320142015

Figure 2. Death toll resulting from heatstroke (2006-2015)

\subsubsection{Heatstroke deaths by industry (2008-2015)}

According to the data on the occurrence of fatal heatstroke accidents by industry during the past eight years (2008-2015) in Figure 3, most accidents occurred in the construction industry which was followed by the manufacturing industry.

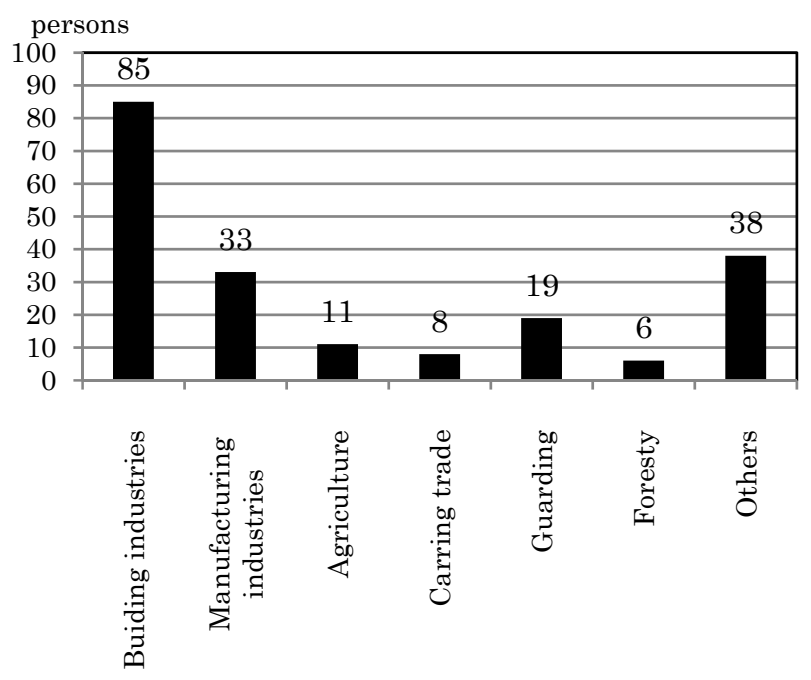

Figure 3. Heatstroke deaths by industry (2008-2015 total)

\subsection{Heatstroke}

Heatstroke is a generic term for physical disorders which occur when the water and sodium balance in the body system fails or the body is no longer able to regulate its internal temperature in a climate of high temperature and high humidity. Its symptoms include dizziness, faint, muscle pains/cramps, excessive perspiration, headache, indisposition, nausea, vomiting, fatigue, despondency, consciousness disorder, convulsion, limb movement disorder, and hyperthermia.

\subsection{People at risk of heatstroke}

Those susceptible to heatstroke include:

*old people

* those who have little sleep, drink alcohol the day before, skip breakfast, or have an obese body.

*those who are under medical treatment for diabetes, high blood pressure, heart disease or psychoneurosis.

* those who do not take in enough water and sodium.

* those who have diarrhea or dehydration.

\subsection{Heatstroke prevention measures}

\subsubsection{Lowering the wet bulb globe temperature (WBGT)}

Wet bulb globe temperature (WBGT) is a heat stress indicator which has been recognized to be effective as an index of working environment and sporting environment, and internationally standardized by ISO and other organizations. ISO7243 was issued as an international standard for working environment, under the title of "Ergonomics of the thermal environment -- Assessment of heat stress using the WBGT index."

Figure 4 demonstrates the relationship between WBGT, dry-bulb temperature and relative humidity. "Guidelines to Prevent Heatstroke in Daily Life ver.3" (2013) issued by the Japanese Society of Biometeorology defines reference temperatures: Danger $\left(31^{\circ} \mathrm{C}\right.$-), Warning $\left(28-31^{\circ} \mathrm{C}\right)$, Alert $\left(25-28^{\circ} \mathrm{C}\right)$, and Caution $\left(-25^{\circ} \mathrm{C}\right)$.

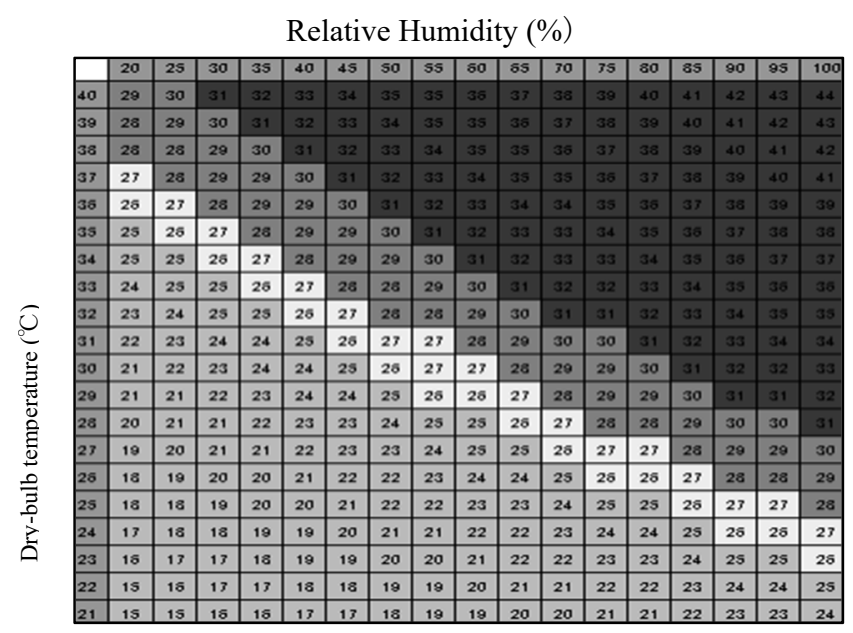

Figure 4. Relationship between WBGT and dry-bulb temperature - relative humidity

Efforts should be made to decrease WBGT in the workplace by taking the following measures.

(1) Place a shield between heat source and workers to block the heat in the workplace where a measured WBGT value has exceeded or will possibly exceed its standard value (hereafter, a hot and humid workplace). 
(2) Install a roof to easily block direct sunlight and reflection off surrounding wall and ground in a hot and humid outdoor workplace.

(3) Equip a hot and humid workplace with a proper ventilation or air-conditioning facility. The facility installed in a hot and humid indoor workplace should have a dehumidifying function. After water sprinkled in an ill-ventilated hot and humid workplace, caution should be taken not to raise the humidity.

\subsubsection{Making arrangements of facilities in a rest area}

Efforts should be made to arrange a rest area for workers by taking the following measures.

(1) Provide a rest area near a hot and humid workplace, which is equipped with an air-conditioner or kept cool in the shade, affording ample space for lying down.

(2) Prepare items and facilities to cool the body off properly such as ice, cooling towels, a cold bath and a shower in or near a hot and humid workplace. Drinking water must be provided in a hot and humid workplace so that workers can take water and sodium regularly and easily.

\subsection{Work management}

\subsubsection{Shortened working hours}

According to working conditions, efforts should be made to take heatstroke prevention measures such as making continuous working time shorter in a hot and humid workplace by securing downtime and break time; avoiding a work which require a higher physical working capacity (metabolic rate); and changing working places.

\subsubsection{Heat acclimatization}

When a worker needs to be assigned to labor in a hot and humid workplace, heat acclimatization (adapting to heat in a given environment) is an effective way to diminish the risk of heatstroke. Thus, it is recommended to afford a planned heat acclimatization period. Particularly from a rainy season to a summer season, it must be noticed that a worker is not yet acclimatized to heat in most cases when he/she stays in a hot and humid workplace where a temperature rises rapidly; when that work is newly launched; or when he/she has been away from that work and resumes it after a long while.

The followings are important points related to heat acclimatization.

(a) Heat exposure time for an unacclimated worker must be gradually increased by spending more than seven days.

(b) Discontinuation of heat exposure causes the deacclimation to start clearly in four days and heat acclimatization will vanish completely after three to four weeks.

\section{Summary}

This study suggested the significance of building construction management which places emphasis on risk prevention for the sake of environment and safety, with the introduction of Japanese efficient operation methods to simultaneously conduct environmental management, safety management and risk management, in addition to practical measures for heatstroke which is a serious summer issue of building construction management. Especially, since ISO45001 was newly issued on March 12,2018 as the international standard of occupational health and safety management systems, Japan has been striving to efficiently avoid risks by promptly introducing ISOs related to environment and safety. As the number of heatstroke patients starts to increase from as early as April in Japan, whether it is under the influence of global warming or not, it is urgently necessary to avoid risks by setting up a comprehensive management system concerning environment and safety.

\section{References}

1. H. Uda, M. Kajimura, T. Tsuchikawa, T. Tanaka, and F. Matsuura. Study for Evaluation of Dangers in Construction and Maintenance of Building Facilities: The Nature of Accidents and Safety in Building Facilities and Risk Management Procedures (Part 1). Proceedings of the Symposium of the Society of Heating. Air-Conditioning and Sanitary Engineers of Japan. pp.1463-1466. (2009)

2. H. Wariishi, H. Torihama, T. Tanaka, Y. Mikami, and T. Hosokawa. Recent Tendency of Accidents in Building Facilities \& Investigation of Causes of Risk in Each Stage of Construction- Symposium on Building and Urban Environmental Engineering. pp.68-73. (BUEE2013)

3. The Japan Advanced Information Center of Safety and Health. Industrial Accidents Statistics in Web site (www.kensaibou.or.jp).

4. The Japan Construction Occupational Safety and Health Association, Statistics in Web site 